\title{
CADEIA DO BIOGÁS NO OESTE DO PARANÁ: À LUZ DA NOVA ECONOMIA INSTITUCIONAL
}

\author{
BIOGAS CHAIN IN WESTERN PARANÁ: IN LIGHT OF THE NEW INSTITUTIONAL \\ ECONOMICS
}

\author{
Udo Strassburg ${ }^{1}$ \\ Nilton Marques de Oliveira ${ }^{2}$ \\ Weimar Freire da Rocha $\mathrm{Jr}^{3}$
}

\begin{abstract}
RESUMO
Este trabalho tem por objetivo caracterizar a cadeia do Biogás, provindo da atividade suína, no Oeste do estado do Paraná, à luz da Nova Economia Institucional - NEI. Utilizou-se de uma metodologia exploratória com base na literatura. $O$ referencial teórico foi centralizado na Nova Economia Institucional - NEI, em suas três abordagens: o ambiente institucional, o organizacional e o tecnológico. Os resultados apontaram que, em relação ao ambiente institucional, expecificamente ao biogás, praticamente não possui regulamentação. No que diz respeito às organizações, estas estão isoladas, com ações também isoladas, sendo necessário o destaque para o Centro de Estudos do Biogás, da Itaipú, que está investindo em pesquisas e estendendo os conhecimentos adquiridos aos produtores de suínos do Oeste paranaense. O ambiente tecnológico está estruturado no sentido de oferecer recursos para a produção de biogás, faltando definições claras e adequadas para o excedente de produção. Sendo assim, o que está sendo necessário para a expansão da produção do biogás no Oeste do Paraná são estímulos do governo no sentido de regulamentar adequadamente a atividade e oferecer incentivos para a produção de energia renovável, tão necessária para o mundo atual.
\end{abstract}

Palavras-Chave: Nova Economia Institucional, Biogás, Atividade suína

\section{ABSTRACT}

This work aims to characterize the chain of biogas, coming from swine activity in western Paraná state, in light of the New Institutional Economics - NEI. We used an exploratory methodology based on the literature. The theoretical framework was centered on New Institutional Economics - NEI, in its three approaches: institutional, organizational and technological environment. The results showed that, compared to the institutional environment, specific of biogas, has practically no regulation. Regarding organizations, these are isolated, with also isolated actions, the highlight for the Centre for the Study of Biogas, the Itaipu, which is investing in research and extending their knowledge

\footnotetext{
${ }^{1}$ Doutorando em Desenvolvimento Regional da Universidade Estadual do Oeste do Paraná - UNIOESTE, Toledo. Professor do Centro de Ciências Sociais Aplicadas da Universidade Estadual do Oeste do Paraná, campus Cascavel. E-mail: udo.strassburg@unioeste.br

${ }^{2}$ Doutorando em Desenvolvimento Regional da Universidade Estadual do Oeste do Paraná - UNIOESTE. Professor do Departamento de Economia da Universidade Federal de Tocantins. E-mail: niltonmarques@uft.edu.br

${ }^{3}$ Engenheiro Agrônomo. Doutor em Engenharia de Produção pela Universidade Federal de Santa Catarina. Professor do Centro de Ciências Sociais Aplicadas da Universidade Estadual do Oeste do Paraná, campus de Toledo. E-mail: wrochajr2000@gmail.com
} 
to pig producers in western Paraná. The technological environment is structured in order to provide resources for the production of biogas, lacking clear and adequate definitions for surplus production. So what is required for the expansion of the biogas production in western Paraná are government incentives in order to adequately regulate the activity and provide incentives for the production of renewable energy so necessary for today's world.

Key-Words: New Institutional Economics, Biogas, swine Activity

JEL: Q2

\section{INTRODUÇÃO}

No mundo, a produção de energias renováveis está ganhando importância pelo fato que esta não agride ao meio ambiente. Por outro lado, a energia não renovável que está sendo utilizada pela maioria dos países causa danos e agreções ao meio ambiente. Outra preocupação se situa nos países em desenvolvimento que necessitam de uma crescente demanda de energia para que possam se desenvolver e crescer.

Galeffi (2013), destaca que a produção de Biogás no mundo irá crescer $60 \%$ nos próximos cinco anos, impulsionado pela necessidade do mercado, como também pelas tecnologias a serem utilizadas. Outro fator destacado por ele é que a potência das instalações industriais que produzem biogás no mundo irá aumentar para cerca de 7,3 GWe em 2016, destacando que em 2012 a potência era de 4,7 GWe. Estes são dados que comprovam o uso da energia renovável obtida com Mecanismos de Desenvolvimento Limpo (MDL).

No Brasil, esta situação é um pouco diferente, pois os investimentos neste setor ainda são pequenos, se comparados ao que é investido na Alemanha, que é uma das maiores produtoras e tem cerca de 6.600 instalações produzindo biogás. Enquanto que no mundo estão ativas aproximadamente 10 mil instalações produtoras de biogás.

A expectativa é grande em termos de incrementos financeiros para que possam ser realizadas pesquisas, no sentido de desenvolver, criar, descobrir ou aperfeiçoar fontes de energia que possam redundar em reflexos importantes para a matriz energética brasileira.

No Oeste do Paraná, foi criado um Centro de Estudos do Biogás, situado em Foz do Iguaçu, nas dependências do Parque Tecnológico de Itaipú, que faz parte das instalações da Usina Hidrelétrica de Itaipú. Este tem trabalhado no sentido de firmar convênios com associações, condomínios e produtores rurais que queiram aplicar e trabalhar com a tecnologia desenvolvida por eles. Alguns condomínios, granjas, associações e cooperativas do Oeste do Paraná já estão trabalhando em conjunto, obtendo resultados positivos. Entre esta cooperação destaca-se a cidade de Entre Rios do Oeste que em breve poderá se tornar autossuficiente em energia elétrica, térmica e automotiva, provinda de dejetos de animais e do esgoto produzido na cidade.

Desta forma, esse ensaio tem como objetivo caracterizar a cadeia do Biogás, oriundo da atividade suína, no Oeste do estado do Paraná, à luz da Nova Economia Institucional, enfocando as abordagens Institucional, Organizacional e Tecnológica. 
O presente trabalho se justifica pelas crescentes discussões sobre o assunto na tentativa de buscar soluções. Pela conscientização que todos devem ter em relação ao cuidado com o meio ambiente. Pelo aproveitamento de algo que é um problema para os produtores, se transformando em recursos financeiros para os mesmos. E pela contribuição de um estudo sobre formas de se produzir energia renovável, tão necessária para a preservação do meio ambiente.

Para a elaboração do presente trabalho utilizaram-se os seguintes procedimentos metodológicos: quantos aos objetivos a pesquisa é exploratória; quanto aos procedimentos é uma pesquisa de fonte de papel; quanto ao objeto é uma pesquisa bibliográfica; e quanto a abordagem é uma pesquisa qualitativa. A pesquisa tem como base a literatura sobre o tema, como livros, revistas, reportagens, material promocional e o auxílio da internet.

Isto posto, este ensaio está dividido em quatro partes, além desta introdução. A seguir será apresentado a Nova Economia Institucional - NEl e seus diversos ambientes. Na terceira parte serão discutidos os Ambientes Institucional, Organizacional e Tecnológico na Cadeia do Biogás. E por fim, as considerações finais encerram o trabalho.

\section{A NOVA ECONOMIA INSTITUCIONAL - NEI}

Nesta seção aborda-se o conceito e os pressupostos da Nova Economia Institucional (NEI), com enfoque no ambiente institucional, organizacional e tecnológico.

A Nova Economia Institucional (NEI) é considerada uma extensão e expansão da economia neoclássica. Extensão por concentrar-se na teoria dos preços e por ser "neo-utilitarista", uma vez que as instituições são derivadas de interesses. E expansão por relatar os pressupostos de informação perfeita e racionalidade e, consequentemente, de mercados perfeitos (TIGRE, 1998). Nas palavras de Toyoshima (1999); Gala (2003); Bueno (2004), a NEI não surgiu da contraposição à teoria neoclássica e sim como uma ampliação de seus postulados.

Os principais autores que deram suporte à teoria da NEI foram Ronald Coase, Oliver Williamson e Douglas North, sendo Coase considerado o pai dessa escola (RUTHERFORD, 1994; CONCEIÇÃO, 2002). Coase (1998) destaca que as instituições são as que governam o desempenho de uma economia e é isso que dá importância ao conceito da NEI para a economia. Coase desenvolveu o conceito de custos de transação, utilizado tanto por Williamson quanto por North, embora de modo distinto.

A NEI, na visão de Williamson (1996) e Coase (1998), tem por objetivo estudar as relações entre instituições e eficiência, e há, para isso, duas vertentes que abordam esses temas: o ambiente institucional e as instituições de governança. A primeira aborda o papel das instituições investigando os efeitos das mudanças no ambiente institucional sobre o resultado econômico, dedicando-se mais especificamente ao estudo das "regras do jogo". A segunda tem por função analisar as transações com um enfoque nas estruturas de 
governança que coordenam os agentes econômicos que lidam com os custos de transação.

Para Farina (2000), as duas correntes têm o objetivo de analisar a economia dos custos de transação e são complementares, apesar de tratarem de níveis analíticos distintos. Ambas recorrem a conceitos comuns e metodologia compatível, de maneira que a sua evolução está ocorrendo de modo sincronizado. Existe uma série de conceitos comuns entre as duas vertentes destacando-se os custos de transação, instituições, organizações e contratos.

Na concepção de North (1991), a NEI consiste na relação interdisciplinar nas áreas de Direito, Economia e da Teoria das Organizações (organização, instituição e transação). Sustenta-se na tese de que a operação e a eficiência de um sistema são limitadas por um conjunto de instituições construídas pelos seres humanos, que interagem na relação social, política e econômica. Na NEl, as instituições são definidas como restrições formais (constituição, leis, direitos de propriedade) ou informais (tabus, tradições, costumes e religião), ou seja, como as regras do jogo econômico, social, político ou do próprio jogo institucional.

A vertente do ambiente institucional trabalha nas relações entre instituições e desenvolvimento econômico, enquanto que a das estruturas de governança estuda as transações, a partir de uma abordagem contratual, sendo complementares. Williamson (1993), com a Teoria dos Custos de Transações (TCT) propôs que a estrutura de governança se desenvolve dentro dos limites impostos pelo ambiente institucional e pelos pressupostos comportamentais dos indivíduos (oportunismo e racionalidade limitada). Willianson, no entanto, reduz as dimensões históricas e sociais das instituições, considerando que as características dos indivíduos e as regras sociais são "dadas" e atribuem importância secundária à path dependence, isto é, a firma lida com estruturas de governança conhecidas, não sujeitas aos processos de aprendizado e aos ambientes em mutação.

Na outra vertente, Douglass North se posiciona da seguinte forma, a NEI é uma tentativa de superar o dilema entre o conhecimento econômico histórico e teórico. Sua análise recai sobre o conceito histórico, dando ênfase na matriz institucional e no conceito do path dependence. Na matriz institucional, o destaque vai para sua capacidade de produzir os incentivos à difusão das relações capitalistas de produção e de troca. O path dependence explica os resultados econômicos alcançados em função de decisões passadas, mas não das condições presentes (NORTH,1994).

\subsection{Ambiente Institucional}

A proposta da Nova Economia Institucional são as instituições, estas se constituem o principal regulador das atividades e interações humanas. Douglas North (1990), expõe em sua obra um marco analítico para explicar como as instituições e as mudanças institucionais afetam a economia: "as instituições existem devido à incerteza que resulta da interação humana" (NORTH, 1999, p.14). North (1990), parte da ideia de Coase (1937), com a premissa que o 
mercado produz custos para a economia e que a diminuição destes são decorrentes da existência de instituições.

Dessa forma, instituições reduzem incertezas porque proporcionam uma estrutura à vida diária, constituindo um processo para a interação humana, que incluem todo tipo de limitação que as pessoas criam para tornar possível a vida em sociedade, com base no respeito às regras (AREND \& CARIO, 2005).

Na sua definição, Douglas North (1991, p. 3) diz que "as Instituições são as regras do jogo", ou mais formalmente, são as restrições humanas criadas as quais moldam a interação humana. As instituições estruturam os incentivos na troca humana, seja política, social ou econômica. Estas moldam o modo como a sociedade evolue ao longo do tempo e, portanto, é a chave para a compreensão da mudança histórica. As instituições formam a estrutura de uma sociedade, constituindo os fundamentos determinantes do desempenho, tanto econômico e social, quanto político. O tempo histórico relacionado à mudança econômica e social é a dimensão na qual o processo de aprendizagem dos seres humanos produz a forma como as instituições evoluem (NORTH, 1991).

As instituições representam, ao longo da história, a manutenção da ordem e a redução das incertezas nas sociedades. Elas são importantes no sistema econômico quando existem diferentes níveis de informação entre os agentes econômicos, de incerteza no mercado e grande número de concorrentes. Há de considerar, também, os custos de transação que criam pontos críticos no desempenho econômico. Diante desses fatores de incerteza, é necessário que haja regras que orientem a direção a ser tomada, para que os problemas relacionados às interações entre os agentes sejam resolvidos, e para que os acordos sejam cumpridos (NORTH, 1991).

Exposto dessa forma, percebe-se, assim, que as instituições figuram como os limites estabelecidos pelo homem a fim de estruturar sua própria interação. Na concepção de Cárdenas \& Ojeda (2002), as regras formais ou intencionais são criadas com um propósito específico. As regras formais incluem questões, jurídicas, econômicas, contratuais e políticas. Já as informais nascem do próprio indivíduo de uma ação coletiva, herdadas de geração em geração, são os nossos costumes, cultura, religião entre outras. As instituições informais influenciam as formais (verbi gratia, qualquer costume nacional se transforma em lei); por outro lado, instituições formais se relacionam com instituições informais (verbi gratia, uma lei que se transforma em costume). Assim, as instituições formais e informais diferem por diversos motivos: nas instituições formais ocorrem mudanças em menor espaço de tempo, precisam da ação coerciva do Estado para serem observadas; as instituições informais, por sua vez, não necessitam de ação coerciva do Estado, pois dependem das crenças do seu povo. As crenças não mudam no curto prazo, pelo contrário, demoram muito tempo para se consolidarem (ESTEVÃO, 2004).

Enfim, as instituições, segundo (North, 1991), ocupam um lugar central na análise do processo de desenvolvimento econômico, porque definem o ambiente em que funciona a economia e promovem a interação entre as pessoas, e porque a mudança institucional define o modo como a sociedade evolui no tempo. 


\subsection{Ambiente Organizacional}

O ambiente organizacional surge a partir de diversas organizações na busca de diferentes objetivos. Nas palavras de North (1991), as organizações são os principais agentes de uma sociedade e dentro dessa categoria encontram-se os mais diversos entes, que são: corpos políticos (partidos políticos, Senado, câmara dos deputados, agências reguladoras); corpos econômicos (empresas, sindicatos, sítios, cooperativas); corpos sociais (igrejas, clubes, associações desportivas); e organizações educativas (escolas, universidades, centro vocacionais de capacitação).

Essas organizações buscam se especializar e adquirir conhecimento para que possam crescer, sejam nas áreas políticas, econômica ou social. Os setores que as organizações atuam são definidos pela matriz institucional vigente, em que as organizações buscam canalizar seus recursos para os setores, aumentando as chances de sobrevivência (NORTH, 1994).

Na visão de Parada (2003), as organizações são contituídas por grupos de indivíduos envolvidos em interesses comuns e com objetivos certos. As instituições determinam organizações e, ao mesmo tempo, essas organizações interferem no desempenho das instituições.

Para Gala (2003), as organizações surgem do framework institucional de uma sociedade num determinado momento do tempo. Daí por diante, passam a interagir com outras organizações, com as próprias instituições e com as tradicionais restrições da teoria econômica. Dessa interação, surge 0 desempenho econômico das diferentes sociedades, bem como sua trajetória instituicional e, ao longo do processo histórico, as diversas organizações esforçam-se das mais variadas maneiras, buscando melhores pay-offs para suas ações.

Para Rocha Jr. (2001); Penna \& Penna (2009), os indivíduos têm como prioridade otimizar suas ações para atingir seus objetivos, eles se unem em grupo, pois presumem que terão mais chances de sucesso do que se atuassem sozinhos. Dessa união se desenvolvem atividades de interesse comum, e consequentemente aumentam a probabilidade de sucesso de suas atividades. A frequência das organizações nas atividades econômicas constitui uma ferramenta indutora da coerência e competência interna e do desempenho externo.

Assim, de acordo com North (1991), as organizações podem investir em atividades econômicas socialmente produtivas, verbi gratia em novas tecnologias de produção, podem investir em atividades redistributivas, na própria alteração das regras do jogo, mudando a matriz institucional sob a qual estão operando.

Para Saes (2000), as organizações podem ser consideradas como uma rede de contratos, que incluem controles e incentivos, mas os mecanismos de governança não se reduzem a tais contratos. Como os indivíduos têm sua racionalidade limitada e comportamento oportunista, esses elementos acentuam ainda mais a incompletude contratual. Assim, Williamson (1996) reforça o papel das organizações no controle e cumprimento de contratos estabelecidos, dizendo uma estrutura de governança é um conjunto de 
instituições inter-relacionadas, com a capacidade de garantir a integridade de uma transação.

As instituições possuem mecanismos de incentivo para que os membros ajam de acordo com a organização. Na visão de Saes (2000), os mecanismos de incentivo são instrumentos para agregar o grupo em um interesse comum. Mecanismos de controle relacionam-se com o fluxo de informações que a organização procura obter de cada um de seus integrantes.

As organizações, portanto, são consideradas os agentes principais de mudança institucional na teoria de North (1991). Todavia, são as instituições formais e informais, que estão relacionadas à sua gênese e ao modo com esta se relaciona dentro de um cenário regional de crescimento e mudança institucional.

\subsection{Ambiente Tecnológico}

A tecnologia é um dos principais fatores, segundo Rocha Jr. (2001), que influencia a competitividade das organizações. Juntamente com o ambiente institucional e o organizacional definem-se o ambiente competitivo de uma atividade econômica regendo e condicionando as ações e estratégias dos agentes econômicos.

$\mathrm{Na}$ concepção de Schumpeter (1961), as inovações e as novas tecnologias são impulsos fundamentais do caráter evolutivo do capitalismo. Revolucionam a estrutura econômica a partir de dentro, em ciclos econômicos (revolução ou absorção dos seus resultados), retirando o interesse, a utilidade, destruindo o antigo e criando novos elementos, com outras utilidades. É o processo de destruição criadora.

Mudanças progressivas de produtos e processos em pequena escala são inovações incrementais; eventos descontínuos que promovem mudanças mais drásticas, porém, localizadas, constituem as inovações radicais e as mudanças de sistemas tecnológicos são capazes de não só afetar partes da economia, mas de gerar novos ambientes tecnológicos e novas indústrias (FREEMAN e PEREZ, 1988).

Para Dosi (1982), a tecnologia tem sido um dos elementos que explicam as estruturas industriais e o comportamento competitivo dos setores e das empresas, podendo ser definida como conjunto de partes do conhecimento prático e teórico, perícia, métodos, processos e experiências de sucessos e fracassos.

As inovações tecnológicas e organizacionais têm possibilitado uma nova trajetória para a organização interna da firma e sua interação com o mercado. Mais precisamente, as inovações nos meios de comunicação e de transporte. No século $X X$, as grandes empresas de equipamentos de geração, transmissão e distribuição de energia, químicas, fertilizantes e de petróleo passaram a liderar a indústria mundial. Os mercados agro-industrial e eletrônico exigem elevados investimentos em atividades de pesquisa e desenvolvimento (P\&D) e serviços, por sua vez uma maior capacidade organizacional (FREEMAN e PEREZ, 1988). 
A similaridade entre tecnologia e ciência é muito forte, uma vez que as mesmas utilizam processos de busca de resolução dos problemas, tendo a capacidade de predição. Quanto mais se consegue obter uma das duas características, maior será a possbilidade de começar a desenvolver um processo de troca ou atualização tecnológica.

As novas mudanças tecnológicas desenvolvidas durante a década de 1970 estavam relacionadas à ciência da computação, às telecomunicações e à mecânica de precisão, estas vieram impor mais desafios no setor tecnológico. Formando-se assim um novo paradigma tecnológico-organizacional, combinando a revolução microeletrônica, originada nos Estados Unidos, com o modelo de organização enxuta e flexível, desenvolvido inicialmente no Japão (NAKANO, 1994). As inovações passaram a ter como base a informação, produção mais complexa e sujeita à incerteza do que a de uma mercadoria tangível, difícil apropriabilidade e possível indivisibilidade.

Isso terminou gerando novas trajetórias para a organização interna da firma, tornando uma necessidade para o seu crescimento a interação com o mercado. No curto prazo, segundo Dosi (1982), o desenvolvimento de um paradigma tecnológico não considera 0 ambiente institucional e fatores socieconômicos, uma vez que os critérios econômicos e tecnológicos são elementos substitutos dentro do próprio paradigma. O critério econômico irá ser um forte elemento que selecionará a tecnologia. No longo prazo, outras variáveis ganham importância e podem exercer grande influência no paradigma. No entanto, o processo de seleção entre paradigmas, é fundamental na combinação de fatores econômicos, institucionais e sociais.

Isto posto, faz-se necessário conhecer de que forma estão operando os ambientes aqui descritos, na cadeia do biogás. De forma mais precisa, conhecer o ambiente institucional, organizacional e tecnológico do biogás do Oeste do Paraná proveniente da criação de suínos.

\section{OS AMBIENTES INSTITUCIONAL, ORGANIZACIONAL E TECNOLÓGICO NA CADEIA DO BIOGÁS}

A cadeia do biogás tem início com as Leis, normas e agências reguladoras que dizem respeito à suinocultura, conforme apresentado na Figura 1.

Figura 1: Demonstrativo da Geração do Biogás 


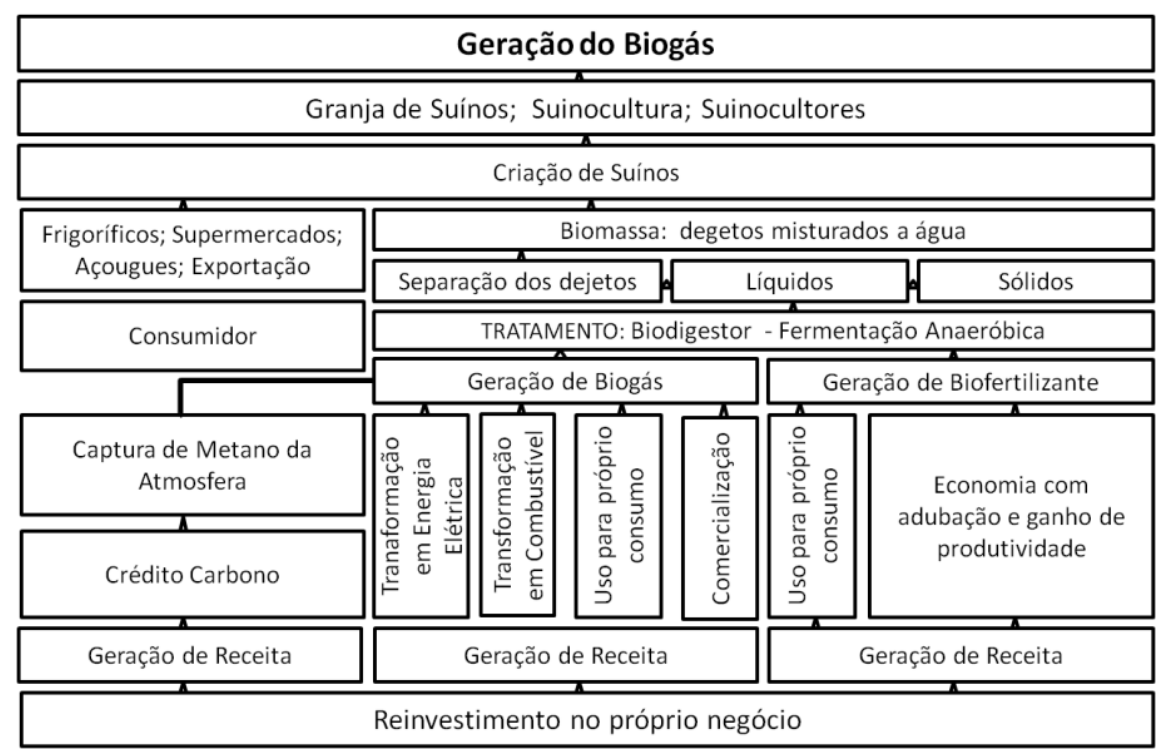

Fonte: Elaboração Própria.

A atividade suinocultora, que está em crescimento no Brasil, tem potencial de geração da energia alternativa que tanto o país necessita para suprir a crescente demanda com o crescimento da economia. Faz-se necessário conhecer um pouco mais sobre os ambientes que compõem a NEI, nesta atividade.

\subsection{O Ambiente Institucional Referente a Atividade Suína/Biogás no Oeste do Estado do Paraná}

A atividade de criação de suínos é uma atividade significativa para 0 país e vem crescendo gradativamente. Segundo a ABPA (2015), no Brasil o abete de suínos no ano de 2014 foi de 3.471 .700 toneladas, enquanto que o Paraná contribuiu com $20,04 \%$ deste total, correspondendo a 695.728 toneladas, destacando que o Oeste Paranaense contribuiu de forma significativa a este montante. Em relação ao destino da produção brasileira, o mercado interno é responsável por $85,8 \%$, correspondendo a 2.978 .718 toneladas, e as exportações consomem 14,2\%, do que é abatido, correspondendo a 492.981 toneladas. Além de que para produzir esta quantidade de carne é necessário pessoas trabalhando, direta e indiretamente, e conforme Willer et al (2010), estão envolvidos na criação de suínos 21.824 pessoas e no abate 279.486, dados do Ministério do Trabalho e Emprego (2010). Esta é a questão social da atividade.

A legislação que trata de questões relativas à atividade de criação de suínos e à geração de biogás e seus derivados inicia na Constituição da República Federativa do Brasil, quando se refere aos cuidados com o meio ambiente, até as últimas criações, alterações e inclusões de leis e projetos de leis, que se referem ao assunto. No quadro 1 , foram relacionadas às atividades dos órgãos envolvidos, sejam Federais, Estaduais ou Municipais. 


\section{Quadro 1 - Ambiente Institucional para a atividade suína e de biogás}

\begin{tabular}{|c|c|}
\hline & $\begin{array}{l}\text { ção da República Federativa do Brasil - Capítulo } \\
\text { neio ambiente, Arts. 5o, LXXIII, 21, XIX, 22, IV, 23, VI, } \\
\text { II, VIII, 129, III, 170, VI, 186, II, 225 }\end{array}$ \\
\hline & as \\
\hline 21 & $\begin{array}{l}\text { das Nações Unidas sobre o Meio Ambiente e o } \\
\text { nento }\end{array}$ \\
\hline & ntre países para combate às mudanças climáticas \\
\hline $1 / 09$ Fed. & Clima \\
\hline $8 / 81$ Fed. & $s p$ \\
\hline i $\quad$ Fed. & $\begin{array}{l}\text { Dispõe sobre a Política Agrícola - Conselho Nacional de } \\
\text { Política Agrícola. }\end{array}$ \\
\hline 07 Fed. & $\begin{array}{l}\text { Dispõe sobre as Diretrizes Nacionais para o Saneamento } \\
\text { Básico }\end{array}$ \\
\hline $305 / 10^{\text {Fed. }}$ & $\begin{array}{l}\text { onal de Resíduos Sólidos - Inclusive } \\
\text { oris }\end{array}$ \\
\hline 197 Fed. & $\cos$ \\
\hline Fed. & e adm. de condutas e \\
\hline Fed. & lítica Nacional de Educação \\
\hline 0 & $\begin{array}{ll}I I & d a \\
\text { lades }\end{array}$ \\
\hline${ }_{1 / 12}^{\text {Fed. }}$ & - Cadastro \\
\hline $2^{\text {Fed. }}$ & bre \\
\hline 11 Fed. & $\begin{array}{l}\text { ental e } 0 \\
\text { is }\end{array}$ \\
\hline $\begin{array}{l}\text { Lei Fed. } \\
12.484 / 11\end{array}$ & $\begin{array}{l}\text { Política Nacional de Incentivo ao Manejo Sustentado, ao } \\
\text { Cultivo do Bambu }\end{array}$ \\
\hline Fed. & ção da vegetação nativa do Bioma Mata \\
\hline $84 / 06^{\text {Fed. }}$ & $\begin{array}{l}\text { sobre a gestão de florestas públicas para a produção } \\
\text { ável; institui, na estrutura do Ministério do Meio } \\
\text { te, o Serviço Florestal Brasileiro - SFB; cria o Fundo } \\
\text { al de Desenvolvimento Florestal - FNDF }\end{array}$ \\
\hline $8 / 01$ Fed. & $\begin{array}{l}\text { sobre a seleção de locais, a construção, o } \\
\text { amento, a operação, a fiscalização, os custos, a } \\
\text { zação, a responsabilidade civil e as garantias referentes } \\
\text { pósitos de rejeitos radioativos }\end{array}$ \\
\hline Fed. & \\
\hline
\end{tabular}




\begin{tabular}{|c|c|}
\hline & $\begin{array}{l}\text { Regulamenta a Lei n. } 12.305 \text {, de dois de agosto de 2010, que } \\
\text { institui a Política Nacional de Resíduos Sólidos, cria o Comitê } \\
\text { Interministerial da Política Nacional de Resíduos Sólidos e o } \\
\text { Comitê Orientador para a Implantação dos Sistemas de } \\
\text { Logística Reversa }\end{array}$ \\
\hline $\begin{array}{l}\text { Decreto } \\
24.643 / 34\end{array}$ & Código das Águas \\
\hline $\begin{array}{l}\text { Lei } 11.268 / 04 \\
\text { - Curitiba }\end{array}$ & $\begin{array}{l}\text { icípio de Curitiba a conceder o uso do Aterro } \\
\text { ximba para exploração do biogás }\end{array}$ \\
\hline $\begin{array}{l}\text { Lei } 17 t \\
\text { Maring }\end{array}$ & $\begin{array}{l}\text { municipal, à proceder em } \\
\text { de reaproveitamento do } \\
\text { - biogás }\end{array}$ \\
\hline $\begin{array}{l}\text { Proje } \\
\text { do } \mathrm{B}\end{array}$ & $\begin{array}{l}\text { Projeto de Lei do estado do PR, que institui normas para a } \\
\text { exploração das atividades econômicas de geração de } \\
\text { energias com biogás originado do tratamento sanitário de } \\
\text { resíduos e efluentes orgânicos, em especial os gerados em } \\
\text { atividades de produção agropecuária e agroindustrial, } \\
\text { protocolado em 13/03/2013 }\end{array}$ \\
\hline $\begin{array}{ll}\text { Res. } & \text { SE } \\
31 / 98 & \end{array}$ & $\begin{array}{l}\text { Dispõe sobre licenciamento ambiental, autorização ambiental } \\
\text { e outros procedimentos. }\end{array}$ \\
\hline $\begin{array}{l}\text { Instr. } \\
\text { Normativo } \\
\text { ANEL } \\
390 / 2009\end{array}$ & $\begin{array}{l}\text { para compra de } \\
\text { es }\end{array}$ \\
\hline $\begin{array}{l}\text { Instr. } \quad \text { Norm. } \\
\text { 105.006/09 }\end{array}$ & $\begin{array}{l}\text { As características dos empreendimentos, critérios - inclusive } \\
\text { locacionais e técnicos, procedimentos, trâmite administrativo, } \\
\text { níveis de competência e premissas para o Licenciamento } \\
\text { Ambiental de Empreendimentos de Suinocultura. }\end{array}$ \\
\hline Embrapa 2003 & $\begin{array}{l}\text { Dispõe sobre proteção ambiental, manejo de dejetos, } \\
\text { biofertilizantes e biogás }\end{array}$ \\
\hline
\end{tabular}

Fonte: Elaboração Própria.

O ambiente institucional para a atividade suína e de geração de biogás ainda não está totalmente estruturado, faltando questões específicas sobre as duas atividades. A legislação encontrada possui ligação indireta, se referindo às questões gerais, abordando questões ambientais, pois a atividade suína é uma grande poluidora pela quantidade de dejetos que a atividade produz. Uma das referências está relacionada ao desenvolvimento sustentável da atividade, aproveitando os dejetos para gerar outros produtos e ainda poder utilizar o biofertilizante para o fortalecimento da área cultivada. Neste sentido, a Agenda 21 e o Protocolo de Quioto são pontos fundamentais para a diminuição de gases que aumentam o aquecimento global.

Uma das Leis que abordam o assunto é a 12.305/10 que trata sobre a Política Nacional de Resíduos Sólidos e os resíduos das atividades agrosilvopastoris. 
Outra Lei que irá causar uma ação de cuidado com os resíduos é a 12.651/12, que instituiu o Novo Código Florestal e dentre as determinações está a criação do $\mathrm{CAR}^{4}$ - Cadastro Ambiental Rural.

Neste sentido, verifica-se que a fiscalização em relação à forma como é dado o destino aos dejetos da atividade suína será intensificada, forçando assim o produtor a aderir a atividades ambientalmente corretas, produzindo biogás.

No Paraná, está tramitando um Projeto de Lei que institui normas para a exploração das atividades econômicas de geração de energias com biogás, originado do tratamento sanitário de resíduos e efluentes orgânicos, em especial os gerados em atividades de produção agropecuária e agroindustrial, encaminhados pelos deputados Elton Welter e Hermas Brandão Junior em 13/03/2013.

Estas são as regras do jogo econômico da atividade de criação de suínos e consequentemente para a geração de biogás, biofertilizante, possibilitando obter algum retorno com a venda de crédito de carbono. Estas regras aumentarão a confiança e estímularão os atores a tomarem suas decisões, no âmbito das organizações econômicas e políticas, fortalecendo assim, o capital social.

Portanto, quando as organizações estiverem fundamentadas em regras bem definidas, possibilitando que o seu desempenho possa ser melhor, as instituições são tratadas como as regras do jogo e as organizações como os jogadores, North (1991).

\subsection{Ambiente Organizacional: Referente a atividade suína/biogás no Estado do Paraná}

O mercado do biogás no Paraná ainda está incipiente, isto que no Oeste do estado estão situadas algumas organizações que trabalham com afinco e dedicação para que possam se fortalecer, fato este que será relatado mais adiante.

O ambiente organizacional da atividade suína, e mais propriamente dito, do biogás está sofrendo grandes transformações visto que é um setor que está ganhando importância, estando, as energias renováveis colocadas em destaque pela incessante busca de diversos países por fontes alternativas de energia.

Como já foi assinalado, a atividade suína é forte e promissora e não deve sofrer contestações, o que precisa ser prestado atenção é se o ambiente organizacional está regulado por um ambiente institucional bem estruturado, pois é este que dará suporte para que aquele possa se desenvolver e progredir de maneira expressiva.

\footnotetext{
${ }^{4}$ O CAR é uma espécie de licenciamento ambiental onde o agricultor estaria garantindo que a sua propriedade está ambientalmente correta, preservando as nascentes, mananciais, rios e áreas de preservação permanente. Com isto pode ter alguns benefícios como empréstimos com juros menores e facilidades no acesso aos recursos, enquanto aquele que não possui o cadastro ainda terá dificuldade de conseguir um financiamento.
} 
O ambiente organizacional da atividade suína/biogás é formado basicamente por associações, sindicatos e cooperativas, as quais serão listadas no Quadro 2:

Quadro 2 - Ambiente Organizacional para a atividade suína e de biogás

\begin{tabular}{|c|c|}
\hline ABCS & Associação Brasileira dos Criadores de Suínos \\
\hline ABEAM & Associação Brasileira de Energias Renováveis \\
\hline ABIPECS & $\begin{array}{l}\text { Associação da Indústria Produtora e Exportadora de Carne } \\
\text { suína }\end{array}$ \\
\hline APS & Associação Paranaense de Suinocultores \\
\hline Toledo-PR & Associação Municipal de Suinocultores de Toledo \\
\hline Suínosul & $\begin{array}{l}\text { Associação Regional de Suinocultores do Centro Sul do } \\
\text { Paraná - Curitiba-PR }\end{array}$ \\
\hline Sindicato & Sindicato Nacional de Suinocultores \\
\hline Sindicarne & $\begin{array}{l}\text { Sindicato da Indústria de carnes e derivados do estado do } \\
\text { Paraná }\end{array}$ \\
\hline Suínosul & Bolsa de Suínos do Paraná - Curitiba - PR \\
\hline Suinco & Cooperativa Nacional de Suinocultores \\
\hline Suicooper & Cooperativa de Suinocultores do Sudoeste do Paraná \\
\hline Catanduvas & Cooperativa de Suín \\
\hline Coop. ABC & $\begin{array}{l}\text { As Cooperativas Castrolanda, Batavo e Capal - Frigorífico de } \\
\text { Suínos }\end{array}$ \\
\hline Cooperlac & $\begin{array}{l}\text { Cooperativa dos produtores de Suínos e Leite do Paraná - } \\
\text { Toledo }\end{array}$ \\
\hline Cooperbiogás & $\begin{array}{l}\text { O projeto do Condomínio de Agroenergia para Agricultura } \\
\text { Familiar da Microbacia do Rio Ajuricaba é desenvolvido pela } \\
\text { Itaipu desde agosto de 2009, em parceria com Emater-PR, } \\
\text { Copel, Prefeitura Municipal de Marechal Cândido Rondon, } \\
\text { Embrapa, Movimento Nacional dos Pequenos Agricultores } \\
\text { (MPA), Instituto de Tecnologia Aplicada e Inovação (ITAI) e a } \\
\text { Fundação Parque Tecnológico Itaipu (FPTI). }\end{array}$ \\
\hline Itaipú & Centro de Estudos do Biogás \\
\hline Itaipu - PTI & s- Labo \\
\hline OER & $\begin{array}{l}\text { Observatório de Energias Renováveis para a América Latina e } \\
\text { o Caribe }\end{array}$ \\
\hline Ajuricaba & $\begin{array}{l}\text { Condomínio de agroenergia com biogás para agricultura } \\
\text { familiar / Ajuricaba }\end{array}$ \\
\hline $\begin{array}{l}\text { Lajeado } \\
\text { Grande }\end{array}$ & Condomínio de Bioenergia Lajeado Grande - Toledo PR \\
\hline Biotol & Empresa Municipal de Biogás - Toledo - PR \\
\hline Copel & $\begin{array}{l}\text { Companhia Paranaense de Energia - Distribuição da energia } \\
\text { gerada }\end{array}$ \\
\hline & \\
\hline
\end{tabular}

Fonte: Elaboração Própria

Organizações brasileiras e paranaenses relacionadas ao Quadro 2 estão bem articuladas no que se refere à atividade suína, pois já possuem uma 
estrutura voltada para a defesa e a divulgação da carne suína, principalmente para que a população passe a consumir mais este tipo de carne. Isto está sendo uma realidade, tanto é que a produção de suínos vem aumentando paulatinamente, conforme está destacado nos dados da ABPA 2015, em que 2008 eram abatidos 3.026 .400 toneladas e em 2014, 3.471.700 toneladas, com um crescimento de 14,71\%, em 7 anos. Em relação ao biogás articulação ainda está faltando, pois nem todos possuem esta consciência de que o investimento nesta área pode trazer retorno para o seu negócio, seja individualmente ou participando de alguma associação, sindicato, cooperativa, condomínio.

Em relação às associações, foram elencadas organizações que possuem a sua abrangência nacional, estadual ou local. Como destaque estão a Associação Municipal de Suinocultores de Toledo e a Associação Regional de Suinocultores do Centro Sul do Paraná - SUINOSUL, que devido a sua mobilização e organização local fortalecem as suas atividades.

Os sindicatos são aqueles que irão representar os produtores nas demandas que podem surgir, dando suporte a atividade.

As cooperativas, centro de estudos, observatórios, condomínios, empresas municipais, possuem uma grande importância para 0 desenvolvimento da atividade, principalmente no que se refere ao biogás. São nestas organizações que serão discutidas as necessidades do setor, o seu futuro, articulando questões relativas à lobbys, negociações, reivindicações, pesquisas, fiscalização, política que contribuam para o desenvolvimento da atividade.

A Copel e a Compagás estariam entrando com o knowhow que possuem na distribuição da energia e do biogás produzido neste processo.

Conforme Zanella (2012), os motivos da fraca atuação das organizações voltadas para o biogás são:

O custo de implantação do biodigestor ser elevado; não ter muito incentivo de intuições públicas; dificuldade em aprovação de projetos além de serem altamente burocráticos; dificuldade no transporte do biogás, o qual acarreta problemas logísticos de carga, descarga, compressão, estocagem e purificação do gás, além da utilização do fertilizante final, fonte de baixa densidade energética (ZANELLA, 2012 p.48).

Assim pode-se verificar que as organizações necessitam ser fortalecidas para que possam superar estas dificuldades que são enfrentadas no processo de geração do biogás e a sua colocação no mercado.

\subsection{O Ambiente Tecnológico: Na atividade suína/biogás no Oeste do Estado do Paraná}

Ao estar inovando, seja no sentido de mudança de visão, de procedimentos, de equipamentos, de metodologia, de produto, de estratégia, etc, está-se investindo em tecnologia. $E$ foi isto que aconteceu com a atividade 
suína, que estando diante de um problema, em virtude dos resíduos deixados pela produção de suínos, considerada uma das atividades mais poluidoras do meio ambiente, sendo também pressionados pelos órgãos ambientais, olhou para este problema com outros olhos e enxergou algo que poderia vir em benefício da própria atividade. Desta forma, Freeman e Perez (1988) destacam que estas mudanças podem ser caracterizadas como inovações incrementais ou inovações radicais.

$\mathrm{Na}$ atividade suína, foi realizada os dois tipos de inovações com resultados significativos, tanto no processo de criação, em melhoria de técnicas da genética e até na questão dos custos. Conforme Batista (2002), o custo de produção de suínos no Brasil, no ano de 2001 era um dos mais baixos, produzindo o $\mathrm{kg}$ de carne a US\$0,63, enquanto que nos EUA o custo do $\mathrm{kg}$ é de US\$0,99, na Espanha US\$1,18 e na França é de US\$1,27. Mas como o foco do presente trabalho está na produção de biogás, serão destacadas as tecnologias referentes a ele.

Antes de se pensar em utilizar os dejetos dos suínos como matéria prima para produção de biogás e biofertilizante, estes eram passados por um decantador para separar a parte sólida e líquida dos mesmos. A líquida, que se destaca pelo volume maior, era tratada por meio de três tipos de lagoas, ligadas em série, com a função de remover os coliformes fecais, matéria orgânica e NPK (Nitrogênio, Fósforo e Potássio). O resultado deste trabalho era utilizado como adubação orgânica PERDOMO et al (1999).

A fase inicial do processo com o biodigestor é parecida, mas com diversas inovações incrementais e radicais. As inovações se dão desde a construção do chiqueirão com recursos para a captação da água da chuva, que será auxiliado por uma motobomba para distribuição adequada da mesma. $\mathrm{O}$ chiqueirão será construído em sistema gravitacional de evasão dos dejetos, que seguirão até o biodigestor. De acordo com Quadros:

O biodigestor é uma câmera fechada onde é colocado material orgânico para decomposição. Pode ser um tanque revestido e coberto por manta impermeável de PVC, com exceção dos tubos de entrada e saída, é totalmente vedado, criando um ambiente anaeróbico (sem a presença de oxigênio) (QUADROS, 2009 p.11).

O biodigestor pode ser de diversos tamanhos, dependendo do volume de dejetos que a propriedade produz. Ligado ao biodigestor está uma motobomba que será a encarregada da circulação dos dejetos no interior do biodigestor, um motor gerador de energia elétrica que irá transformar o biogás em energia e uma lagoa para depósito de chorume, ou seja, de biofertilizante.

A lagoa com biofertilizante estará ligada a mais uma motobomba que estará bombeando este até ao pulverizador, que estará aspergindo na lavoura, pasto e demais plantas existentes no local, sendo conduzido por canos para irrigação, previamente preparados. O biogás produzido será também utilizado como combustível para as três motobombas citadas anteriormente e para o gerador de energia. A energia elétrica gerada será utilizada para a iluminação e 
outras necessidades do chiqueirão, para a iluminação das residências da propriedade rural e também para a iluminação externa. $O$ excedente de energia elétrica poderá ser vendido para a concessionária de energia elétrica conveniada. Esta descrição está demonstrada na Figura 2.

\section{Figura 2- Esquema de ligação do biogás}

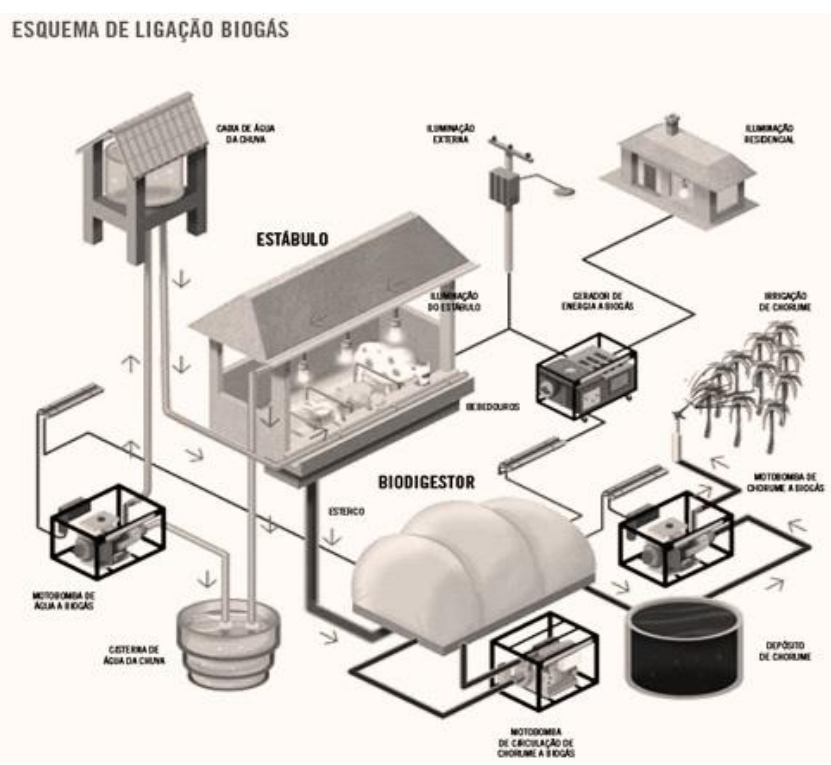

Fonte: https://superbanco.wordpress.com/tag/bio-gas/

Para fazer frente aos produtos e serviços com a intenção de viabilizar um esquema como este que foi apresentado, o mercado oferece diversas opções de tamanho, potência, capacidade e de empresas fornecedoras.

Além de ser utilizado o biogás para a geração de energia elétrica e de fornecer energia para tocar o gerador e os motobombas, Walsh citado por Santos (2000), apresenta outras utilidades na Figura 3:

Figura 3- Principais formas de uso do biogás 


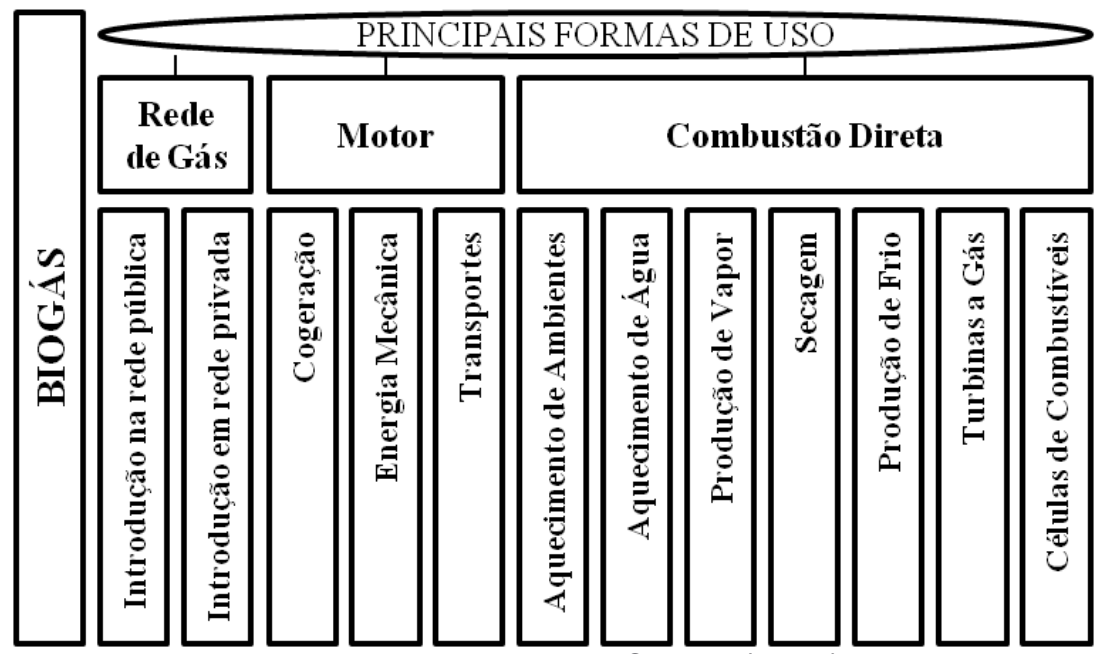

Fonte: Adaptado de Walsh citado por Santos (2000)

Outra forma de utilização de tecnologia para o biogás está relacionada aos painéis de controle - que controlarão a entrada e a saída de energia para que não haja acidentes. Estas são as tecnologias que estão disponíveis para consumo, as quais estão sendo utilizadas pelos condomínios e por grandes produtores da região Oeste do Paraná e também há estudos e pesquisas para aperfeiçoamento destas e o desenvolvimento de outras. Estas pesquisas e estudos estão sendo desenvolvidos pelo Cibiogás, instalado nas dependências da ITAIPÚ.

\section{CONSIDERAÇÕES FINAIS}

Neste trabalho, foi apresentado e discutido a Nova Economia Institucional - NEl em suas três abordagens: o ambiente institucional, 0 organizacional e o tecnológico. Logo após foi colocado os resultados da investigação do biogás na atividade suína sob a perspectiva da NEl.

Para a elaboração do presente trabalho utilizou-se de uma metodologia exploratória com base na literatura sobre o tema.

Neste sentido, verificou-se que as instituições voltadas para a atividade suína estão bem estruturadas no sentido de possuírem uma regulamentação específica, como leis, decretos e instruções normativas, e também dão ênfase à melhoria e incentivo à produção, divulgação de seus produtos, enfatizando a necessidade dos brasileiros consumirem mais a carne suína, destacando a melhoria na genética dos animais, a crescente produção e consequente colocação no mercado interno e externo. Já em relação à regulamentação específica para o biogás, praticamente não existe. A atividade se baseia em normas específicas para o meio ambiente.

No ambiente organizacional, foi encontrado ações relativas à atividade suína, assim como no institucional. Foram encontradas associações de abrangência nacional, estadual e municipal; sindicatos nacional e estadual e cooperativas com representação nacional, estadual, regional e local. $\mathrm{Na}$ questão relacionada ao biogás foram verificadas ações isoladas abrangendo 
poucas localidades. Estas ações são realizadas por intermédio de associações, condomínios, cooperativas, centro de estudo que estão atuando com abrangência regional, mas no futuro pretendem ampliar seus horizontes.

A abordagem no ambiente tecnológico foi específica para a atividade de produção do biogás, em que foi verificado se existe tecnologia de ponta no que diz respeito à produção para consumo próprio, mas para o excedente esta tecnologia ainda não está bem difundida.

Portanto chegou-se à conclusão que o Brasil é um importante agente para a produção de energia renovável, especialmente o biogás, tendo este um grande potencial para a matriz energética brasileira. Também verificou-se que para a expansão da produção do biogás no Brasil há uma dependência de estímulos do governo no sentido de estar regulamentando a atividade, deixando bem claro o começo, o meio e o final do processo de produção. Isso possibilita que as organizações possam se fortalecer e investir no negócio e que a tecnologia disponibilizada para o setor possa ser direcionada para atender às necessidadees dos produtores e usuários.

Em relação a estas ações isoladas foi dado ênfase para o caso do Oeste do Paraná, com o Centro de Estudos do Biogás instalado na Itaipú, que está oferecendo excelentes serviços de pesquisa e extensão, contribuindo assim para o desenvolvimento e crescimento da atividade de exploração do biogás no Brasil.

Como sugestão para trabalhos futuros, seria interessante a apresentação de estudos de casos e pesquisas de campo para verificar a viabilidade, a rentabilidade e a satisfação daqueles que estão investindo e acreditando na produção do biogás.

\section{REFERÊNCIAS}

ABPA - Associação Brasileira de Proteína Animal, Relatório Anual 2015, http://abpa-br.com.br/files/RelatorioAnual_UBABEF_2015_DIGITAL.pdf, Acesso em: 31/07/2015.

AREND, M.; CÁRIO, S. A. F. Origens e determinantes dos desequilíbrios no Rio Grande do Sul: uma análise a partir da teoria institucional de Douglass North. Ensaios FEE, Porto Alegre, v. 26, p. 63-94, maio, 2005.

BATISTA, P. S., O caminho do sucesso passa pelo porto. ANUALPEC, 2002, p. 286-287.

BUENO, N. P. Lógica da ação coletiva, instituições e crescimento econômico: uma resenha temática sobre a nova economia institucional. Economia, Brasília, DF, v.5, n. 2, p. 361-420, jul./dez., 2004.

CÁRDENAS, E.; OJEDA, J. La nueva economía institucional y la teoría de la implementación. Revista de Economia Institucional, Bogotá, v. 4, n. 6, 2002.

COASE, R. H. The nature of the firm. Economica, n. 4, nov., 1937. 
The new institutional economics. The American Economic Review, Cambridge, Mass., v. 88, n.2, p. 72-74, maio, 1998.

CONCEIÇÃO, O. A. C. O conceito de instituição nas modernas abordagens institucionalistas. Revista de Economia Contemporânea, Rio de Janeiro, v.6, n.2, p. 119-146, jul./dez., 2002a.

DOSI, G. Technological paradigms and technological trajectories. A suggested interpretation of determinants and directions of technical change. Research Policy, Amsterdam, v. 11, n. 3, p. 147-162, 1982.

ESTÊVÃO, J. Desenvolvimento econômico e mudança institucional: o papel do Estado. In: CONFERÊNCIA INTERNACIONAL ECONOMIC POLICIES IN THE NEW MILLENIUM, 2004, Coimbra. Anais...Coimbra, Portugal: FEUC, abr. 2004.

FARINA, E. M.M. Q. Organização industrial no agribusiness. In: ZYLBERSZTAJN, D.; NEVES, M. F. (Org.) Economia e gestão de negócios agroalimentares. São Paulo: Pioneira, 2000, Cap. 3.

FREEMAN, C., PEREZ, C. Structural crises of adjustment, business cycles and investment behavior. In: DOSI, G. et al. Technical change and economic theory. London: Pinter Publishers, 1988. p. 38-66.

GALA, P. A Teoria institucional de Douglass North. Revista de Economia Política, v. 23, n. 2, abr./jun., 2003.

GALEFFI, C. Biogás no mundo, publicado em 17/06/2013, http://www.portalresiduossolidos.com/biogas-no-mundo-carlo-galeffi/, Acesso em 11/02/2014.

MINISTÉRIO DO TRABALHO E DO EMRPEGO. Relação Anual de Informações, 2010.

NAKANO, Y. Globalização, competitividade e novas regas de comércio mundial. Revista de Economia Política, ano 14, v.4, n, 56, p. 7-39, 1994.

NORTH, D. C. . Institutions, Institutional change and Economic Performance - Political Economy of Institutions and Decisions. New York: Cambridge University Press, 1990.

$112,1991$.

Institutions. Journal of Economic Perspectives. v.5, n.1, p. 97-

. Economic performance through time. The American Economic Review, Cambridge, Mass., v.84, n.3, p. 359-368, 1994.

"Understanding the process of Economic Change", lea Occasional Paper, London, 1999.

PARADA, J. J. Economia institucional original y nueva economía institucional: semejanzas y diferencias. Revista de Economia Institucional, Bogotá, v.5, n.8, 2003.

PENNA, A. B.; PENNA, L. B. Cultura organizacional: um estudo de sua estruturação e de sua correlação com poder dentre empresários rurais setelagoanos. Revista FACEVV, n. 2, 1º sem. de 2009. 
PERDOMO, C. C., et al, Dimensionamento de sistemas de tratamento (decantador de lagoas) e utilização de dejetos suínos, Comunicado Técnico 234, Embrapa Suínos e Aves, Abril/1999, p. 1-5.

QUADROS, D. G., Biodigestor na agricultura familiar do Semiárido, Salvador: EDUNEB, 2009.

ROCHA JÚNIOR, W. F. da. Análise do Agronegócio da Erva-Mate com o enfoque da Nova Economia Institucional e o uso da matriz estrutural prospectiva. Tese de Doutorado apresentada ao Programa de Pós-Graduação em Engenharia de Produção. Florianopolis: UFSC, 2001.

RUTHERFORD $M$. Institutions in economics: the old and the new institutionalism. Cambridge: Cambridge University Press, 1994.

SAES, M. S. M. Organizações e Instituições. In: ZYLBERSZTAJN, D.; NEVES, M. F. (Org.) Economia e gestão de negócios agroalimentares. São Paulo: Pioneira, 2000, Cap. 8, p. 165-186.

SANTOS, P. Guia técnico de biogás. Portugal: Centro para conservação de energia, 2000.

SCHUMPETER, J. Capitalismo, socialismo e democracia. Rio de Janeiro: Fundo de Cultura, 1961.

TIGRE, P. B. Inovação e teorias da firma em três paradigmas. Revista de Economia Contemporânea, v.3, p.67-111, 1998.

TOYOSHIMA, S. H. Instituições e desenvolvimento econômico: uma análise crítica das idéia de Douglas North. Estudos Econômicos, v. 29, n. 1, 1999.

WILLER, E. M., et al, Distribuição especial da cadeia agroindustrial de suínos no Oeste Paranaense, In: CONGRESSO BRASILEIRO DE ECONOMIA E SOCIOLOGIA RURAL DA SOBER, 48., 2010, Campo Grande, MS. Anais... Campo Grande, MS, 2010.

WILLIAMSON, O. The mechanism of governance. New York: Oxford University Press, 1996 429p.

Transaction cost economics and organization theory. Industrial and Corporate Change, v.2, n.2, p. 107-156, 1993.

ZANELLA, M. G., Ambiente Institucional e Políticas Públicas para o Biogás proveniente da Suinocultura. Dissertação de Mestrado em Bioenergia da UNIOESTE/ Toledo-PR, 2012.

https://superbanco.wordpress.com/tag/bio-gas/, Esquema de Ligação do Biogás. Acesso em: 31/07/2015.

Submetido em: 20/03/15

Aceito em: 19/08/15 